\title{
Sensitivity of Yield and Fruit Quality of French Prune to Water Deprivation at Different Fruit Growth Stages
}

\author{
Bruce D. Lampinen, Kenneth A. Shackel, Stephen M. Southwick, Bill Olson, and \\ James T. Yeager \\ Department of Pomology, University of Caliornia, Davis, CA 95616 \\ Dave Goldhamer \\ Department of Land, Air and Water Resources, University of California, Davis, CA 95616
}

Additional index words. deficit irrigation. flowering, fruit growth stage, stem water potential, water stress

\begin{abstract}
The sensitivity of French prune (Prunus domestica L. syn. 'Petite d'Agen') to water deprivation at various fruit growth stages was studied over 3 years in a drip-irrigated orchard. The soil was a poorly drained Rocklin fine sandy loam with a hardpan that varied from 4.75 to $\mathrm{I} \mathrm{m}$ from the surface at the northern end of the orchard (shallow soil condition) to no hardpan apparent to $2 \mathrm{~m}$ below the surface at the southern end of the orchard (deep soil condition). Water deprivation during a) the first exponential phase of fruit growth or stage I, b) lag phase of fruit growth or stage II, c) first half of stage II, d) second half of stage II, e) second exponential fruit growth phase or stage III, and f) postharvest was compared to a fully watered control. Water deprivation caused the most severe reduction in tree water status when it was imposed over longer periods of time and during periods of high evaporative demand and also had mm-e severe effects under shallow soil conditions. Compared to the control treatment, deprivation during all of stage II (the most severe deprivation treatment) was associated with increased Ilowering, reduced fruit hydration ratio, and smaller fruit size under all soil conditions. Under deep soil conditions, deprivation during all of stage II resulted in increased return bloom, which was reflected in higher fruit loads and dry t-ha-' fruit yield. However, under shallow soil conditions, even though return bloom was increased with this treatment, fruit loads and dry $t^{-h} a^{-1}$ fruit yields were the lowest of all treatments. These differences in treatment effects in shallow vs. deep soil conditions were most likely the result of increased fruit drop, which occurred under shallow soil conditions as a result of rapid onset and increased severity ofstress. Treatments that had parallel effects in shallow and deep soil conditions resulted in statistically significant overall treatment effects, while those that had opposing effects in shallow vs. deep soil conditions did not show significant overall treatment effects. Substantial alternate hearing occurred, and, in general, dry fruit yields above $\approx 9$ dry tha ${ }^{-1}$ resulted in a decrease in fruit load the following year, while loads below this value showed a subsequent increase. Based on a separate estimate of the theoretically stable value for each treatment, all deprivation treatments resulted in a higher sustainable fruit load compared to the fully irrigated control. This suggests that, for the purpose of prune fruit production, there may be an optimal level of tree water stress.
\end{abstract}

California experienced drought cycles from 1976-80 and again from 1985-92. In Spring 1991 and 1992. many growers received reduced or no allocation from irrigation district surface water supplies. During these shortages, growers were faced with allocating limited water to minimize detrimental effects on fruit yield and quality in the short term while striving to maintain healthy trees in the long term. Although weather related droughts are periodic. chronic shortages of agricultural water supplies arc likely due to increased urban and environmental demands.

Previous work on water deprivation in prune has shown that it is relatively tolerant of water stress. Hendrickson and Veihmeyer (1934) showed that it took 4 years of no irrigation to obtain decreased trunk growth and 5 years to obtain decreased fruit yields relative to irrigated control trees. This study was conducted with widely spaced trees on deep valley soils. Both of these factors delay the development and reduce the severity of water stress, especially with high winter rainfall. Prune fruit hydration ratios were shown to be related to crop load, with lower fruit hydration ratios during light crop years (Hendrickson and Veihmeyer, 1939). Fruit hydration ratios have also been shown to be lowered by water

Reccived for publication 7 Feb. 1994. Accepted for publication 10 0ct. 1994. We gratefully acknowledge the statistical advice given by Douglas $V$. Shaw in the preparation of this manuscript. This work supported in part by a grant from the California Prune Board. The cost of publishing this paper was defrayed in part by the payment of page charges. Under postal regulations, this paper therefore must be hereby marked advertisement solely to indicate this fact. deprivation (Hendrickson and Veihmeyer, 1945). Since prunes are used largely as dried fruit, a lower fruit hydration ratio can be beneficial. A study by Proebsting et al. (1981) was designed to determine the minimum amount of water required to keep prune trees alive during severe water shortages. Water deprivation that supplied $50 \%$ and 15\% ET, (crop evapotranspiration) throughout the season reduced yield, fruit size. and trunk growth. However, by the second year after treatment, prune trees were back to normal production. indicating that they are quite tolerant of stress.

Water stress is generally associated with reduced plant productivity (Bradford and Hsiao, 1982). However. some beneficial effects of water stress have been reported in a number of fruit tree crops. Regulated deficit irrigation (RDI) involves stressing trees during particular stages of fruit development and then providing normal or excess water during a Inter period to obtain a horticulturally beneficial response, such as a reduction in vegetative growth while maintaining or increasing fruit growth. RDI during stage II of fruit growth has been shown to reduce vegetative growth without reducing fruit quality and perhaps even increasing yields in peach (Chalmers et al., 1981 : Mitchell and Chalmers. 1982). Li et al.. 1989, reported that, in peach, the sensitivity of variousorgans to water stress ranked as follows: limb diameter increase > shoot elongation growth $>$ fruit growth $>$ expansion in leaf area. They found that deficit irrigation during the first rapid fruit growth and pit-hardening stages led to decreased vegetative growth and increased fruit size. They also found that stress in any fruit growth stage led to decreased fruit drop. Boland et al. (1993) found that 
peach trees used $50 \%$ less water than a fully irrigated control during early season RDI and $30 \%$ less during the remainder of the season, with no negative effects on fruit growth. Mitchell et al. (1984) showed that RDI during periods of rapid vegetative growth in pear decreased vegetative growth but had no effect on fruit growth.

Water deprivation can have detrimental or beneficial effects on flowering depending on the timing and degree of stress. Larson et al. (1988) found that postharvest water stress in peach led to a $40 \%$ increase in return bloom compared to a wet treatment. RDI during specific stages of fruit growth in pear led to increased return bloom (Mitchell et al., 1984; Mitchell et al., 1989). Severe stress has been shown to lead to decreased return bloom in peach (Proebsting et al., 1989) and apricot (Brown, 1953; Uriu, 1964). Return bloom and yield efficiency have been shown to be increased as a result of root restriction resulting from trees being grown in fabric lined trenches (Williamson and Coston, 1990). Deficit drip irrigation may cause the roots in the dry soil (i.e., not under an emitter) to become physiologically inactive, effectively decreasing rooting volume (Chalmers et al., 1983; Mitchell and Chalmers, 1983). Drip irrigation increased yield efficiency while reducing shoot growth compared to overhead sprinklers in apple (Proebsting et al., 1977), which suggests it may have been having an impact by way of root restriction. Proebsting et al. (1989) showed that the effects of water deprivation and root restriction were similar in young peach trees. Root restriction has the potential to be beneficial to fruit tree productivity due to increased yield efficiency and decreased vegetative growth. Since drip irrigation appears to lead to root restricted plants, it may be a useful tool to enhance the effectiveness of deficit irrigation treatments.

Prune growers are hesitant to stress trees during fruit growth, in part because of previous work by Uriu et al. (1962) showing that reirrigation after water deprivation could induce end-cracking. Also, work by Bertrand et al. (1976) showed that postharvest water stress for one season caused significantly larger cankers upon inoculation with mycelium of Cytospora leucostoma. They suggested that the water stress caused a lack of vigor in the trees, which made them more susceptible to parasitization by $C$. leucostoma. Other real or perceived concerns related to water stress are increased fruit drop, decreased fruit size, and increased diseasedamaged fruit. Since the price the grower receives for prunes is influenced by fruit quality and individual fruit size as well as total crop weight, negative effects of stress on any of these factors could have a direct financial impact on the grower.

This paper reports on the effects of water deprivation during various stages of fruit development on flowering, fruit drop, fruit yields, and fruit quality in French prune. The objective of this work was to determine whether the overall productivity of French prune trees was differentially sensitive to water deprivation at these different stages of fruit development.

\section{Materials and Methods}

Experimental site, cultural practices, and statistical design. This study was conducted from 1989 to 1991 in a commercial orchard near Gridley (Butte County), Calif. The site was chosen because the trees were drip-irrigated on a relatively shallow soil known to have a hardpan. The combination of shallow soil and drip irrigation should cause restricted rooting volume, allowing rapid development of water stress following irrigation cutoff. The French prune trees were 7 years old at the start of the study and were planted on Myrobalm 29C (Prunus cerasifera) rootstock. Tree spacing was $4.57 \mathrm{~m}$ between trees by $5.49 \mathrm{~m}$ between rows.

The soil was classified as a poorly drained Rocklin fine sandy loam and had a hardpan over a dense silica or iron-cemented substratum (Carpenter et al., 1926). The hardpan varied from $\approx 0.75$ to $1 \mathrm{~m}$ from the surface at the northern end of the experimental site to no hardpan apparent to $2 \mathrm{~m}$ below the surface at the southern end. These conditions were reflected in initial tree size, which ranged from a trunk cross-sectional area (TCSA) of $100 \mathrm{~cm}^{2}$ at the northern end to $180 \mathrm{~cm}^{2}$ at the southern end.

The grower's drip irrigation system was modified by installing a lateral line equipped with shutoff valves at each plot. Water meters were used to measure applied water. Control irrigation volume was calculated weekly based on estimated crop coefficients (Goldhamer and Snyder, 1989) and modified Penman reference crop water use $\left(\mathrm{ET}_{\mathrm{o}}\right)$ obtained from a nearby weather station (California Irrigation Management Information System Station \#12, Durham, Calif.). The final irrigation decisions were at the discretion of the grower. The actual annual applied water for the control irrigation treatment was $20 \%$ overestimated $\mathrm{ET}_{\mathrm{c}}$ in $1989,4 \%$ under estimated crop water use $\left(\mathrm{ET}_{\mathrm{c}}\right)$ in 1990, and $20 \%$ underestimated $\mathrm{ET}_{\mathrm{c}}$ in 1991.

Nitrogen fertilizer (UN32) was applied at a rate of $232 \mathrm{~kg} \mathrm{~N} / \mathrm{ha}$ through the drip irrigation system. When a deficit treatment was turned off during a fertilizer application, the amount of missed fertilizer was calculated and applied directly below the emitters to minimize fertilization differences among treatments.

A 1.7-ha experiment was established in a randomized complete-block design, with six blocks oriented north to south, perpendicular to the variation in soil depth and tree size, and seven irrigation treatments. Deprivation treatments were based on withholding water during different portions of the phenological stages of fruit growth, with an additional postharvest deprivation treatment as well as a fully irrigated control treatment for all 3 years of the study (Table 1). Each plot consisted of sixteen trees (four rows of four trees), and data were collected separately from each of the four center trees in each plot. Since each tree represented a subsample, it was possible to test for the significance of a block $\mathrm{x}$ treatment interaction effect using the residual mean square (i.e., the sampling error) as the appropriate error for this interaction

Table 1. Description of irrigation treatments, water applied, and annual water savings.

\begin{tabular}{lcccc}
\hline \hline Treatment & $\begin{array}{c}\text { Growth stage } \\
\text { of water } \\
\text { deprivation }\end{array}$ & $\begin{array}{c}\text { Dates of } \\
\text { irrigation } \\
\text { cutoff }\end{array}$ & $\begin{array}{c}\text { 3-Year average } \\
\text { applied water } \\
(\mathrm{mm})\end{array}$ & $\begin{array}{c}\text { Range in annual } \\
\% \text { savings over } \\
\text { control }\end{array}$ \\
\hline D0 & None (control) & None & 836 & 0 \\
D1 & I (early growth stage) & Through 4 May & 810 & $0-9$ \\
D2a & First half II (lag stage) & 5 May-6 June & 704 & $13-24$ \\
D2b & Second half II (lag stage) & 7 June-18 July & 550 & $24-37$ \\
D2 & Entire II (lag stage) & 5 May-18 July & 417 & $37-59$ \\
D3 & III (late growth stage) & 19 July-15 Aug. & 544 & $26-39$ \\
D4 & Postharvest & 15 Aug.-season end & 777 & $5-25$
\end{tabular}


(Steel and Torry, 1980) when the data for each year were analyzed separately. When the data for all years were pooled and analyzed as a split plot in time, however, the same block $\times$ treatment interaction was more appropriately tested using the year $\times$ block $\times$ treatment mean square as an error term.

Tree water relations. Predawn and/or midday water potential were measured every other week using a pressure chamber (Soil Moisture Equipment Corp., Santa Barbara, Calif.). Predawn leaf water potential was measured on 24 basal leaves (per treatment), which were enclosed within foil-covered plastic envelopes just before being severed to avoid errors due to water loss between sampling and measurement (Turner, 1988). Midday water potential was measured on 24 basal leaves per treatment; the leaves were enclosed within foil-covered plastic envelopes at least 1 hour before the midday measurement (midday stem water potential) (McCutchan and Shackel, 1992).

Tree growth and fruiting. A tape dendrometer was used to measure trunk circumference at a marked location $-0.3 \mathrm{~m}$ from the soil surface. These measurements were made three times in 1989 and on a monthly basis in 1990 and 1991.

Flowers were counted just before full bloom on three tagged branches per tree on all four monitored trees per plot in 1990, 1991, and 1992. Flowering was expressed as number of flowers $/ \mathrm{cm}^{2}$ branch cross-sectional area. These same branches were used to measure fruit set at reference date (when $80 \%$ to $90 \%$ of the seeds show the presence of endosperm), which was 10, 4, and 14 May in 1989, 1990, and 1991 respectively.

Five fruit on each of the four monitored trees per plot were tagged early in the season. The tagged fruit were evenly spaced around the tree and at a height of $-2 \mathrm{~m}$ from the ground. Fruit cheek diameter was measured weekly $-3 \mathrm{~h}$ after sunrise on the tagged fruit with a hand-held digital micrometer. Fruit drop (all 3 years) and the initial observation of cracking (1990 and 1991 only) were recorded from these same tagged fruit.

A harvester-mounted load cell was used to measure total fresh prune weight per tree. Subsamples were taken at harvest from each tree and weighed immediately. The samples were dried in a commercial drying facility to $\approx 18 \%$ moisturecontent. Dried samples were weighed and their size distribution was determined. Fruit hydration ratio was determined from these samples by dividing fresh weight by dry weight. Fresh yield per tree was divided by fruit hydration ratio to determine dry yield per tree. In 1990 and 1991, the dried fruit were also scored for side and end cracks if the crack length exceeded $0.6 \mathrm{~cm}$.

Relative dollars/ha return were calculated as an index of overall tree productivity considering tree yield, fruit size distribution, and fruit hydration ratio. Prune field price schedules (Prune Bargaining Association) for 1991 were used as well as average harvesting costs of $\$ 59$, hauling costs of $\$ 3$, and drying costs of $\$ 23 /$ t. These values are for comparison only and do not account for costs of land, pruning, fertilization, irrigation, or other economically important production costs.

\section{Results and Discussion}

Overall irrigation treatment effects. Water deprivation during different stages of fruit development resulted in a range of water savings for the treatments. Treatments that withheld water when crop water requirements were low, such as during stage I (D1), early stage II (D2a), or postharvest (D4), had savings of $25 \%$ or less compared to the control (Table 1). Withholding water during periods of moderate water demand, such as the second half of stage II (D2b) and stage III (D3), saved from $24 \%$ to $39 \%$ over the control, while withholding water during all of stage II (D2) resulted in applied water savings of $37 \%$ to $59 \%$ over the control. Midday stem water potential was well correlated with predawn water potential (data not shown). The average annual midday stem water potential also showed a strong correlation with seasonal applied water (Fig. 1). This indicated that any overall irrigation treatment effects would include a combination of effects due to timing of water deprivation and the degree of water stress experienced by the tree. Since different fruit growth stages are systematically associated with different levels of evaporative demand and crop water requirements in most tree crops, however, it is reasonable to consider the combination of these factors as a treatment effect.

Based on the applied water (Table 1) and the relationship shown in Fig. 1, in terms of the degree of water stress, we may consider treatments PI and D4 as similar to the control, treatment D2a as mild, treatments D2b and D3 as moderate, and treatment D2 as a more severe moisture stress treatment relative to the control. In view of this, it is not possible to compare equivalent stress levels at all fruit growth stages studied. There are practical limitations to. achieving significant stress during fruit growth stage I or the first half of stage II. It was difficult to achieve any more than minor levels of stress in the trees before June. Moderate to severe stress only occurred in the second half of fruit growth stage II or stage III. Therefore, what effect moderate to severe stress in stage I or early stage II would have on prune tree performance or fruit quality remains unknown. Practically, however, this is not a disadvantage, since it would probably not be realistic to achieve moderate to severe stress early in the season due to factors discussed earlier. Differences between treatments D2b and D3 may provide the clearest evidence for a differential sensitivity to the same degree of stress applied at different fruit growth stages.

When an analysis of variance (ANOVA) was performed for each of the three experimental years separately, using yield, fruit size, and other important production characteristics, the effects of treatment, block, and block $\times$ treatment interaction were often found to be significant (data not shown). A significant block $\mathrm{x}$

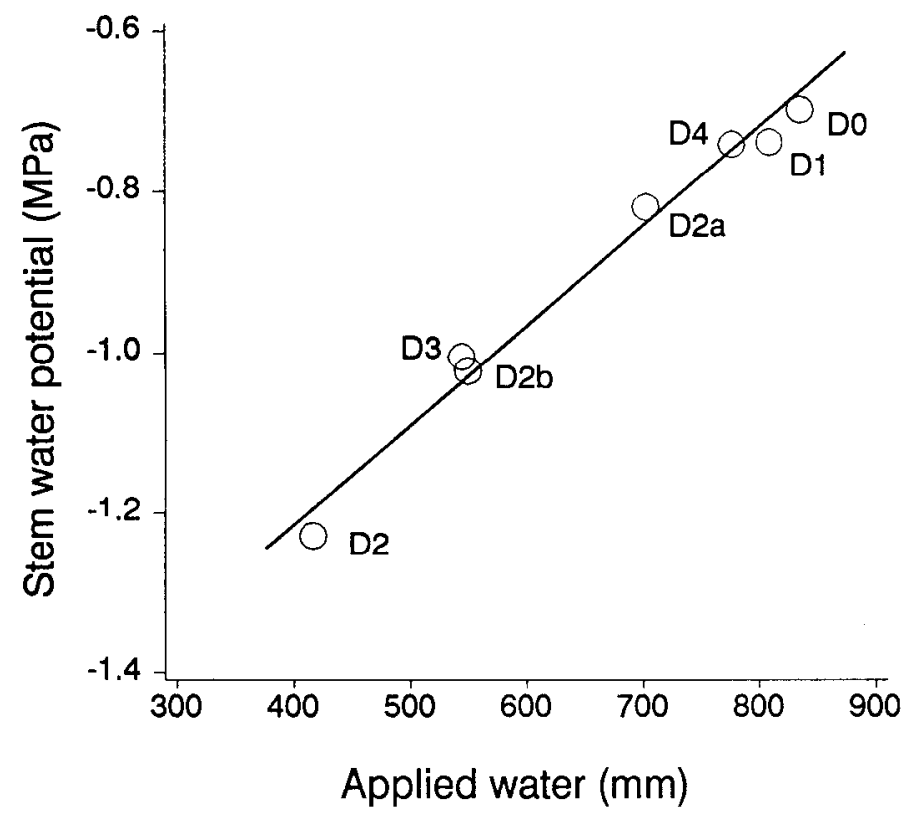

Fig. 1. Correlation of average annual applied water with average seasonal midday stem water potential. Each point represents the 3-year mean for each treatment. The equation of the linear regression is $\mathrm{Y}=0.00123 \mathrm{X}-1.709$ with an $r^{2}$ value of 0.99 . 
treatment interaction indicates that treatment effects were not equivalent in different blocks (see below). For this analysis, however. the sampling error (i.e., the variation among trees in the same four-tree plot) was used to test for the significance of the block $\times$ treatment term, and it was not possible to determine whether the significance found was due to an interaction per se or to the sampling error being an underestimate of the true withinblock random variation. This is a limitation inherent to any experimental design in which treatments arc applied locally to plots within blocks and is analogous to the use of family rows as plots within blocks, as described by Lambeth et al. (1983). When the data for all years were pooled and analyzed as a split plot in time, the main effects of treatments were found to be significant for flowering and fruit quality characteristics. but were not significant for overall production characteristics such as yield (Table 2). Interactive effects were also significant for many characteristics (Table 2). These will be discussed in more detail below. but they do not preclude overall treatment comparisons, since the use of block $\times$ treatment as the error term for testing treatment main effects (Table 2) results in a conservative estimate of treatment significance. The 3-year treatment means showed that the rnoderate (D2b and D3) and severe (D2) stress treatments ranked higher than the control in flowering, although only the most severe (D2) was significantly higher (Table 3). All of the deprivation treatments also ranked above the control for fruit load but there were no significant differences. The mild (D2a), moderate (D2b and D3), and severe stress treatments (D2) had lower fruit hydration ratios compared to the control, although, once again, only the severe stress treatment (D2) was significantly lower. All of the stress treatments ranked above the control for dry $t \cdot h^{-1}$ yields, although there were no significant differences. The moderate (D2b and D3) and severe stress treatment (D2) had higher dry fruit count/kg (i.e., smaller fruit) compared to the control, but only the most severe treatment (D2) was significantly higher. Dried prunes that fall through a $1.8-\mathrm{cm}$ grading screen arc graded as undersize and have little monetary value. There was no statistically significant increase in undersize fruit $(P=0.27)$ for any of the treatments for the 1990 or 1991 crop years. Undersize data was not collected in 1989. All of the stress treatments ranked above the control for relative dollars/ha return, but, as with dry $\mathrm{t} \cdot \mathrm{ha}^{-1}$ yield, there were no significant differences. Lower fruit hydration ratio and increased flowering will influence dry fruit yields and monetary returns positively, while higher count/kg will have a negative influence on monetary returns. Hence the improved fruit hydration ratio and increased flowering that was associated with water deprivation apparently offset the negative physiological effects that are usually associated with water deprivation (Bradford and Hsiao, 1982). Effects such as increased flowering can be beneficial if the increase is within the desirable load range for the tree but detrimental if it causes an excessive load. In the cases of significant differences from the control (Table 3), the most severe stress treatment (D2) was the most different, followed by the two moderate stress treatments (D2b and D3). Hence, these data do not provide any evidence for a differential sensitivity to stress at these stages of fruit growth.

Block and interactive effects. Although treatment main effects

Table 2. Analysis of variance table for selected fruit and tree characteristics.

\begin{tabular}{|c|c|c|c|c|c|c|c|c|}
\hline \multirow[b]{2}{*}{ Source } & \multirow[b]{2}{*}{ df } & \multirow[b]{2}{*}{$\begin{array}{l}\text { Error term used } \\
\text { for F test }\end{array}$} & \multicolumn{6}{|c|}{ Type III mean square and F significance } \\
\hline & & & $\begin{array}{c}\text { Flowers } \\
\left.\text { (no./cm' } \mathrm{BCSA}^{\prime}\right)\end{array}$ & $\begin{array}{c}\text { Fruit load } \\
\left.\text { (no. } / \mathrm{cm}^{2} \text { TCSA }\right)\end{array}$ & $\begin{array}{l}\text { Fruit hydration } \\
\text { ratio }\end{array}$ & $\begin{array}{l}\text { Fruit yield } \\
\left(\text { dry } t \cdot h a^{1}\right)\end{array}$ & $\begin{array}{l}\text { Dry count } \\
\text { (no. fruit/kg) }\end{array}$ & $\begin{array}{l}\text { Monetary return } \\
\text { (dollars/ha) }\end{array}$ \\
\hline Treatment (T) & 6 & $B \times T$ & $1,732^{1+4}$ & $330^{\mathrm{s}}$ & $1.99^{+7+}$ & $20^{\mathrm{Ns}}$ & $7,278^{7 * * *}$ & $8.2 \times 10^{h \mathrm{~ns}}$ \\
\hline Block (B) & 5 & $\mathrm{~B} \times \mathrm{T}$ & $3.791^{\cdots+}$ & $1,763^{1 \cdots}$ & $1.58^{+* i}$ & $153^{+\ldots *}$ & 5.060 & $6.1 \times 10^{h n s}$ \\
\hline $\mathrm{B} \times \mathrm{T}$ & 30 & $Y \times B \times T$ & $493^{\circ}$ & $267^{\wedge s}$ & $0.20^{\circ}$ & $26^{\wedge !}$ & $984^{\prime \prime}$ & $7.0 \times 10^{\mathrm{his}}$ \\
\hline Year $(Y)$ & 2 & $\mathrm{Y} \times \mathrm{B} \times \mathrm{T}$ & $77,284^{\ldots-1 .}$ & $122.406^{i+1}$ & $20.21^{+\cdots+4}$ & $3,145^{+\cdots+\cdots}$ & $1,058,344^{*+}$ & $2.5 \times 10^{63++}$ \\
\hline $\mathrm{Y} \times \mathrm{T}$ & 12 & $\mathrm{Y} \times \mathrm{B} \times \mathrm{T}$ & $1,019^{\circ}$ & $681^{\circ}$ & $0.69^{n+1}$ & $28^{\mathrm{NS}}$ & $2.835^{\wedge}$ & $1.3 .0 \times 10^{1 \mathrm{ss}}$ \\
\hline$Y \times B$ & 10 & $\mathrm{Y} \times \mathrm{B} \times \mathrm{T}$ & $2.464^{\cdots}$ & $1.061^{\circ+}$ & $0.41^{+\infty+1}$ & $66^{\prime \prime \prime}$ & $4,338^{\circ}$ & $11.2 \times 10^{\mathrm{s}} \mathrm{s}$ \\
\hline $\mathrm{Y} \times \mathrm{B} \times \mathrm{T}$ & 60 & Residual & $5000^{1+i}$ & $300^{0 .+4}$ & $0.12^{\prime \prime}$ & $17^{1+\ldots}$ & $1,491^{* *}$ & $7.4 \times 10^{6 \times}$ \\
\hline Residual & 372 & & 23.5 & 63 & 0.07 & 6 & 653 & $4.85 \times 10^{n}$ \\
\hline
\end{tabular}

${ }^{\overline{ }}$ Branch cross-sectional area.

${ }^{\mathrm{y}}$ Trunk cross-sectional area.

NS, ${ }^{*}, * * * *$ Nonsignificant or signifcant at $P \leq 0.05$. 0.01 , or 0.001 , respectively.

Table 3. Ranked least squares (LS) means for fruit load and quality factors for all soil conditions.

\begin{tabular}{|c|c|c|c|c|c|c|c|c|c|c|c|}
\hline \multicolumn{2}{|c|}{$\begin{array}{c}\text { Flowers } \\
\left(n o . / \mathrm{cm}^{2} \mathrm{BCSA}^{\prime}\right)\end{array}$} & \multicolumn{2}{|c|}{$\begin{array}{c}\text { Fruit load } \\
\left.\text { (no./cm } \mathrm{cCSA}^{2}\right)\end{array}$} & \multicolumn{2}{|c|}{$\begin{array}{c}\text { Fruit hydration } \\
\text { ratio }\end{array}$} & \multicolumn{2}{|c|}{$\begin{array}{l}\text { Fruit yield } \\
\left(\text { dry } t \cdot h a^{-1}\right)\end{array}$} & \multicolumn{2}{|c|}{$\begin{array}{c}\text { Dry count } \\
\text { (no. fruit/kg) }\end{array}$} & \multicolumn{2}{|c|}{$\begin{array}{c}\text { Monetary return } \\
\text { (dollars/ha) }\end{array}$} \\
\hline Treatment & LS mean & Ireatment & LS mean & Ireatment & LS mean & 'Treatment & LS mean & Treatment & LS mean & Treatment & LS mean \\
\hline $\mathrm{D} 2$ & $60.1^{*}$ & D3 & 37.1 & D4 & 3.41 & D3 & 11.0 & D2 & $188^{\circ}$ & $\mathrm{D} 2 \mathrm{a}$ & 4717 \\
\hline $\mathrm{D} 2 \mathrm{~b}$ & 52.2 & $\mathrm{D} 2$ & 35.0 & $\mathrm{Dl}$ & 3.32 & D4 & 10.9 & $\mathrm{D} 2 \mathrm{~b}$ & 175 & $\mathrm{D} 1$ & 4643 \\
\hline D3 & 50.7 & D2b & 35.0 & DO & 3.29 & D2 & 10.7 & D3 & 169 & D4 & 4437 \\
\hline $\mathrm{D} 2 \mathrm{a}$ & 50.2 & $\mathrm{D} 4$ & 3.3 .2 & $\mathrm{D} 2 \mathrm{a}$ & 3.25 & D2a & 10.6 & D4 & 167 & $\mathrm{D} 2$ & 4118 \\
\hline Dl & 49.5 & D2a & 32.8 & D3 & 3.10 & DI & 10.6 & Do & 164 & D3 & 4000 \\
\hline Do & 45.7 & $\mathrm{Dl}$ & 32.5 & D2b & 3.10 & D2b & 10.5 & D1 & 160 & Do & 3958 \\
\hline D4 & 15.4 & Do & 30.3 & $\mathrm{D} 2$ & $2.93^{*}$ & Do & 9.3 & $\mathrm{D} 2 \mathrm{a}$ & 150 & $\mathrm{D} 2 \mathrm{~b}$ & 3899 \\
\hline $1 . S D(5 \%)$ & 12.0 & & 8.5 & & 0.15 & & 2.0 & & 8.6 & & 957 \\
\hline
\end{tabular}

${ }^{\overline{ }}$ Branch cross-sectional area.

${ }^{y}$ Trunk cross-sectional area.

*Significant at $P=0.05$ using Dunnett's test (SAS Institute, 1988). 
(Table 2) and treatment means (Table 3) showed some statistically significant differences, the possibility of significant interactions involving blocks indicated that further analysis may be required to interpret these effects. A simple-effects analysis (Steel and Torrie, 1980) was used to determine whether the interaction indicated that treatment effects were in the same direction but simply differed in magnitude in the different blocks or whether there was a reversal of treatment effects in different blocks. Since prune trees are known to bear alternately (Davis, 1931, Ryugo et al., 1977), it is possible that the significance of the year $\times$ block $\times$ treatment interaction (Table 2), subject to the same limitations as discussed above, may have been due to a treatment effect on this alternate- bearing habit. Alternate bearing and the effects of some of the year interactions will be described below.

One important source of block variability in this study was the soil depth to hardpan described earlier. Soil analysis on samples from the shallow soil conditions indicated a loam, while those from the deep soil conditions were classified as a sandy loam to sandy clay loam. This textural difference combined with the difference in depth to hardpan suggested that trees under shallow soil conditions may be differently affected by water deprivation than trees under deep soil conditions.

Midday stem water potential in the various blocks showed that, even though the amount of water applied to the various treatments

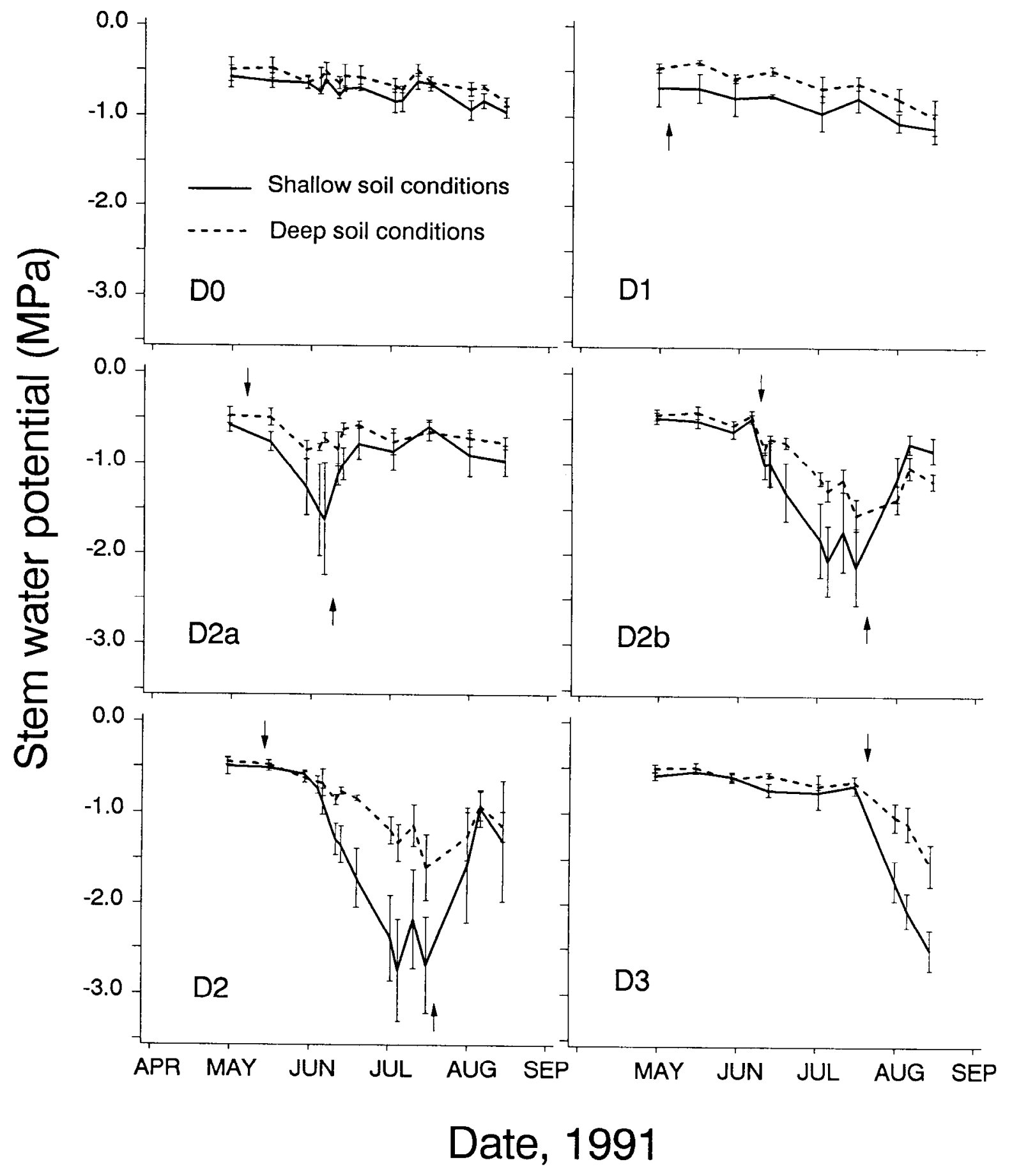

Fig. 2. Seasonal pattern of average midday stem water potential for shallow (blocks 1 and 2) vs. deep (blocks 3-6) soil conditions. Vertical bars are \pm 2 SE. Down arrows indicate irrigation cutoff and up arrows reintroduction. Treatment D2 was turned on -6 days late in 1991 (11 instead of 5 May). 
was the same in all of the blocks, the rate of stress development and final degree of stress achieved varied under different soil conditions (Fig. 2). Under shallow soil conditions, midday stem water potential generally dropped off more rapidly and reached a significantly lower minimum compared to deep soil conditions. For example, D2 reached an average minimum midday stem water potential of about -2.5 and $-1.5 \mathrm{MPa}$ under shallow and deep soil conditions. respectively (Fig. 2). For prune trees, these represent physiologically significant differences in midday stem water potential (McCutchan and Shackel, 1992). Based on this differential in tree water status under shallow vs. deep soil conditions, treatment effects in blocks 1 and 2 and blocks 3 to 6 were analyzed separately.

This difference in treatment severity under shallow vs. deep soil conditions helped to explain why treatment effects on flowering and fruit hydration ratio were significant while treatment effects on production were not. Generally, where treatment effects were significant in the overall analysis of variance (Table 2), there were parallel treatment effects under shallow and deep soil conditions (Table 3). The moderate (D2b and D3) and severe (D2) stress treatments all rank above the control (D0) in flowering and count/ $\mathrm{kg}$ under shallow and deep soil conditions (Table 4) and, overall, there arc significant effects for both of these factors (Table 2). A similar-effect can be seen for fruit hydration ratio, where moderate to severe stress treatments rank below the control under both shallow and deep soil conditions (Table 4), and. again, there is a significant overall treatment effect (Table 3). For fruit load, dry $\mathrm{t} \cdot \mathrm{ha}^{-1}$ yield, and relative dollars/ha return; however, the moderate to severe treatments rank above the control under deep soil conditions but rank mostly below the control under shallow soil conditions (Table 4). and. in these casts, there is no overall treatment significance (Table 3).

The alternate-bearing cycle also exhibited a block $\times$ treatment interaction. The alternate-bearing tendency of prune can be seen when the crop load is plotted vs. year (Fig. 3). For all treatments under deep soil conditions, the crop load was highest in 1989, lowest in 1990, and intermediate in 1991. Under shallow soil conditions. however. the patterns of yield are different for the control (D0) vs. moderate (D2a) and severe (D2) stress treatments. For D0, the trend was the same regardless of soil conditions (Fig. 3a). For D2a and D2, fruit drop in 1989 (a heavy crop year) diminished or reversed the alternate-bearing cycle under shallow soil conditions compared to the pattern exhibited under deep soil conditions (Fig. $3 \mathrm{~b}$ and c). D0 had a fruit drop of 37\%, D2a 55\%, and D3 $75 \%$ under shallow soil conditions in 1989, but these differences were not statistically significant because of high variability $(\mathrm{P}=0.32)$. In $1990 \mathrm{D} 0, \mathrm{D} 2 \mathrm{a}$, and D2 had respective drops of $47 \%, 27 \%$. and $50 \%$ under shallow soil conditions, and, again. these differences were not statistically significant $(\mathrm{P}=0.81)$. In 1991, the respective drops were $35 \%$. 50\%, and $32 \%$ under shallow soil conditions, and, once again. these differences were not statisticallysignificant $(P=0.34)$. There also may have been an effect of flowering since D2a and D2 had more flowers $/ \mathrm{cm}^{2}$ branch cross-sectional area than D0 under all soil conditions although only D2 had significantly more (Table 3). Mitchell et al. (1989) showed that RDI in pear increased flowering and tended to stabilize year-to-year fluctuations in fruit load.

In general, yields above $\approx 9$ dry $\mathrm{t} \cdot \mathrm{ha}^{-1}$ showed a subsequent decrease in fruit load the following year. while lower yields showed a subsequent increase. This indicates that there might be an optimal crop load that the trees could carry every year without increasing or decreasing subsequent crops. Because fruit load has direct and indirect effects on prune tree performance, treatment effects on the pattern of alternation in fruit loads was analyzed by plotting the current-year fruit load at harvest vs. the increase or decrease in fruit load at harvest for the subsequent year (Fig. 4). This figure combines data from all years. Fruit loads below $\approx 20$ fruit $/ \mathrm{cm}^{2}$ TCSA (on the $\mathrm{x}$ axis) result in a subsequent year increase in fruit load (y axis). Fruit loads above $\approx 25 \mathrm{fruit} / \mathrm{cm}^{2} \mathrm{TCSA}$ result in a decrease in load the following year. In theory, the point where

Table 4. Ranked least square means for fruit load and quality factors under shallow (blocks I anti 3) and deep (blocks 3-6) soil conditions.

\begin{tabular}{|c|c|c|c|c|c|c|c|c|c|c|c|}
\hline \multicolumn{2}{|c|}{$\begin{array}{c}\text { Flowers } \\
\left.\text { (no. } / \mathrm{cm}^{2} \mathrm{BCSA}^{\prime}\right)\end{array}$} & \multicolumn{2}{|c|}{$\begin{array}{c}\text { Fruit load } \\
\text { (no. } / \mathrm{cm}^{-2} \text { TCSA') }\end{array}$} & \multicolumn{2}{|c|}{$\begin{array}{c}\text { Fruit hydration } \\
\text { ratio }\end{array}$} & \multicolumn{2}{|c|}{$\begin{array}{l}\text { Fruit yield } \\
\text { (dry tha') }\end{array}$} & \multicolumn{2}{|c|}{$\begin{array}{c}\text { Dry count } \\
\text { (no. fruit } / \mathrm{kg} \text { ) }\end{array}$} & \multicolumn{2}{|c|}{$\begin{array}{l}\text { Monetary return } \\
\text { (dollars/ha) }\end{array}$} \\
\hline Treatment & LS mean & Treatment & LS mein & Treatment & LS mean & Treatment & LS mean & Treatment & LS mean & Treatment & LS mean \\
\hline \multicolumn{12}{|c|}{ Blocks I and 2 (shallow soil conditions) } \\
\hline D2 & $78.9^{\circ}$ & D3 & 31.1 & D4 & 3.29 & Dl & 10.2 & D2 & 178 & D2a & 5645 \\
\hline $\mathrm{D} 2 \mathrm{~b}$ & 63.3 & DI & 30.5 & D) 1 & 3.21 & D4 & 9.9 & D3 & 165 & D4 & 5039 \\
\hline $12 \mathrm{a}$ & 60.3 & Do) & 30.4 & Do) & 3.14 & $\mathrm{D} 2 \mathrm{a}$ & 9.4 & D2b & 162 & Dl & 5013 \\
\hline D 1 & 56.9 & D4 & 29.8 & D3 & 3.03 & Do & 9.3 & $\mathrm{D} 0$ & 159 & Do & 4458 \\
\hline D3 3 & 52.8 & $\mathrm{D}_{2} \mathrm{a}$ & 27.4 & $\mathrm{D} 2 \mathrm{a}$ & 3.01 & D3 & 9.1 & D4 & 156 & $\mathrm{D} 2$ & 4122 \\
\hline D) & 49.2 & $\mathrm{D} 2 \mathrm{~b}$ & 26.8 & $D 2 b$ & $2.91^{\circ}$ & $\mathrm{D} 2 \mathrm{~b}$ & 7.9 & D1 & 154 & $\mathrm{D} 2 \mathrm{~b}$ & 3764 \\
\hline D4 & 48.9 & D2 & 22.2 & $\mathrm{D}^{2}$ & $2.64^{*}$ & $\mathrm{D} 2$ & 7.3 & $\mathrm{D} 2 \mathrm{a}$ & 144 & D3 & 3415 \\
\hline $\operatorname{l.SD}(5 \%)$ & 14.6 & & 9.8 & & 0.27 & & 4.3 & & 30 & & 2532 \\
\hline \multicolumn{12}{|c|}{ Blocks $3,4,5$, and 6 (deep soil conditions) } \\
\hline D2 & 50.8 & $\mathrm{D} 2$ & 41.4 & D4 & 3.48 & D2 & 12.4 & $\mathrm{D} 2$ & $193^{*}$ & D1 & 4459 \\
\hline D3 & 49.7 & $\mathrm{D} 2 \mathrm{~b}$ & $39.0^{\circ}$ & D1 & 3.38 & D3 & $11.9^{\circ}$ & $\mathrm{D} 2 \mathrm{~b}$ & 181 & D3 & 4293 \\
\hline $\mathrm{D} 2 \mathrm{~b}$ & 46.6 & D3 & $38.5^{+}$ & $\mathrm{D} 2 \mathrm{a}$ & 3.38 & $\mathrm{D} 2 \mathrm{~b}$ & 11.8 & D4 & 172 & $\mathrm{D} 2 \mathrm{a}$ & 4253 \\
\hline D1 & 45.9 & D2a & 35.5 & DO) & 3.37 & D4 & 11.3 & D3 & 171 & D4 & 4136 \\
\hline $\mathrm{D} 2 \mathrm{a}$ & 45.2 & D4 & 34.9 & D2b & 3.19 & $\mathrm{D} 2 \mathrm{a}$ & 11.3 & $\mathrm{D}()$ & 167 & $\mathrm{D} 2$ & 4117 \\
\hline Do & 43.9 & DI & 3.3 .5 & D.3 & 3.13 & $\mathrm{DI}$ & 10.8 & $\mathrm{D} 2 \mathrm{a}$ & 166 & $\mathrm{D} 2 \mathrm{~b}$ & 3966 \\
\hline D4 & 43.6 & DO & 30.3 & $\mathrm{D} 2$ & 3.07 & Do & 9.1 & $\mathrm{D} 1$ & 162 & Do & 3708 \\
\hline $\operatorname{LSD}(5 \%)$ & 5.4 & & 4.5 & & 0.13 & & 2.1 & & 12 & & 816 \\
\hline
\end{tabular}

${ }^{\mathrm{z} B r a n c h}$ cross-sectional area.

'Trunk cross-acctional area.

*Significant at $P=0.05$ using Dunnett's test (SAS Institute. 1988). 
each treatment line crosses the $\mathrm{x}$ axis is the fruit load that could be carried by the trees without an increase or decrease in the following year. The stress treatments did not negatively impact this value and in fact, all of the stress treatments had a higher apparent crop load capacity compared to the control treatment. Approximate limits for these values were obtained by inspection of the point where the upper and lower confidence limits for each regression line crossed the $\mathrm{x}$ axis. This indicates that stress might actually allow a higher load to be maintained without alternate bearing compared to the control treatment. Similar rankings of the treatments were obtained regardless of how yield was expressed (e.g., number of fruit/ tree, number of fruit $/ \mathrm{cm}^{2}$ TCSA, dry weight/tree, dry weight $/ \mathrm{cm}$ ' TCSA). However, number of fruit $/ \mathrm{cm}^{2}$ TCSA was used for this analysis because it showed the best overall correlation. For in-

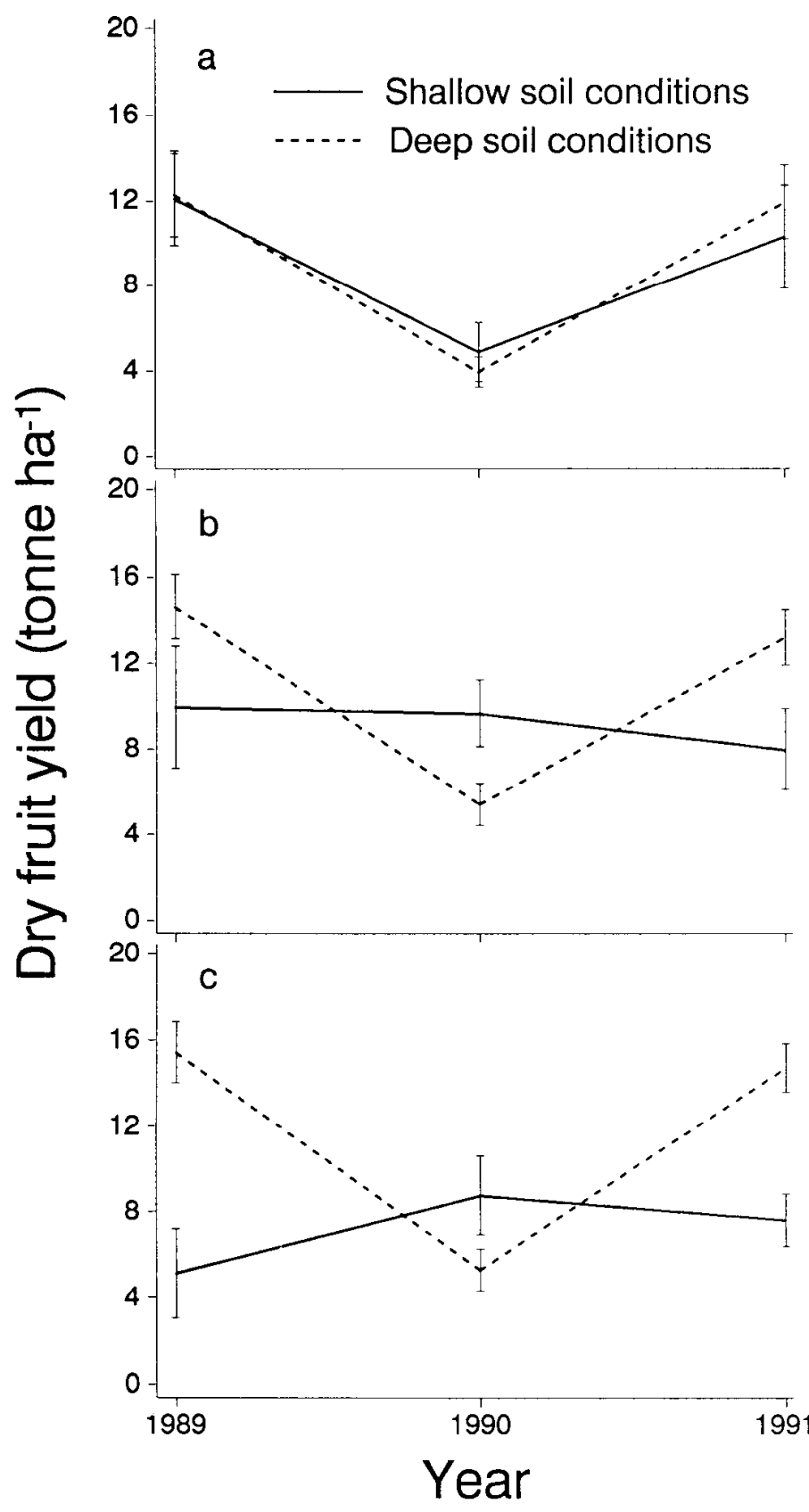

Fig. 3. Three-year trend for average annual dry t-ha ${ }^{-1}$ yield for trees under- shallow (blocks 1 and 2) vs. deep (blocks 3-6) soil conditions for treatment DO (a), D2a (b), and D2 (c). Vertical bars are \pm 2 SE. stance, $r^{2}$ values ranged from 0.93 to 0.97 for number of fruit $/ \mathrm{cm}^{2}$ TCSA compared to a range of 0.81 to 0.93 for the relationship using dry weight/tree or dry weight $/ \mathrm{cm}^{2}$ TCSA.

Previous work on peach (Chalmers et al., 1981: Mitchell and Chalmers. 1982) and pear (Mitchell et al.. 1983) has suggested that RDI can result in altered partitioning of carbon from vegetative to reproductive structures. Although we found some differential sensitivity of prune trees to water deprivation during particular stages of fruit development. most of the effects may have been direct or indirect effects of increased flowering and fruit load and/ or decreased fruit hydration ratios. For instance, there were no significant treatment effects on trunk growth for the 3 years of the study under either shallow $(P=0.12)$ or deep soil conditions $(P=$ 0.46 ; data not shown), suggesting that carbon was not being repartitioned from vegetative to fruit growth. Trunk growth had a strong inverse relationship with fruit load $\left(r^{2}=0.89\right)$, with the most growth occurring during 1990) (a light crop year) and little growth occurring during 1989) (a heavy crop year: data not shown). Although fruit cheek diameters were decreased by the moderate and severe stress treatments, return bloom and resulting fruit loads were increased, which would lead to decreased fruit size independently of any direct water stress effect on fruit sizing. Even D2. which resulted in $\approx 50 \%$ of ET being applied, did not have significant negative impactl on dry $\mathrm{t} \cdot \mathrm{ha}^{-1}$ yields under deep soil conditions, and there was some indication that yields may have been enhanced.

The reversal of some treatment effects relative to the control in different blocks as well as the potential enhancing effect of the stress treatments on the carrying capacity discussed above indcates that, in prunes, there may be a level of stress that is beneficial. Stress during stage II, such as wax seen under deep soil conditions in treatment D2 (midday stem water potential minimum of about $-1.5 \mathrm{MPa}$ ), had an enhancing effect on flowering. fruit load, and yields (Table 4) without increasing fruit drop or cracking (data not shown). More severe stress. as was seen under shallow soil conditions in treatment D2 (midday stem water potential minimum of about -2.5 MPa). also enhanced Ilowering (Table 4) but caused increased fruit drop and increased fruit end-cracking as well (data not shown). Although all treatments showed trunk gumming and there were no significant treatment effects on number of trees showing trunk gumming $(P=0.55)$. an increased severity of trunk gumming for treatment D2 under shallow soil condition:, was observed.

There arc examples in the literature of deficit irrigation being used to enhance economic returns. Hargreaves and Samani (1984) estimated that deficit irrigation can give a higher monetary return per unit land area compared to irrigating for maximum yields in a number of crops in California. In our study, relative dollars/ha return were not significantly higher for any of the treatments under either shallow or deep soil conditions. but, under deep soil conditions, all the deprivation treatments rank above the control in terms of relative dollars/ha return (Table 1). Under shallow soil conditions, mild to moderate deprivation treatments (D1, D4, and D2a) ranked above the control, while the more severe deprivation treatments (D2, D2b, and D3) ranked below the control. again suggesting that there may be a moderate amount of stress that is beneficial to production. Several variables must be considered in making the decision to use deficit irrigation. Costs of irrigation water, rainfall amounts, and crop price are all factors that must be considered. English et al. (1990) showed that deficit irrigation was a profitable strategy for seven wheat farms in the Columbia Basin in the northwestern United States. However, the examples given in English et al. (1990) are for crops that produce lower yields under 


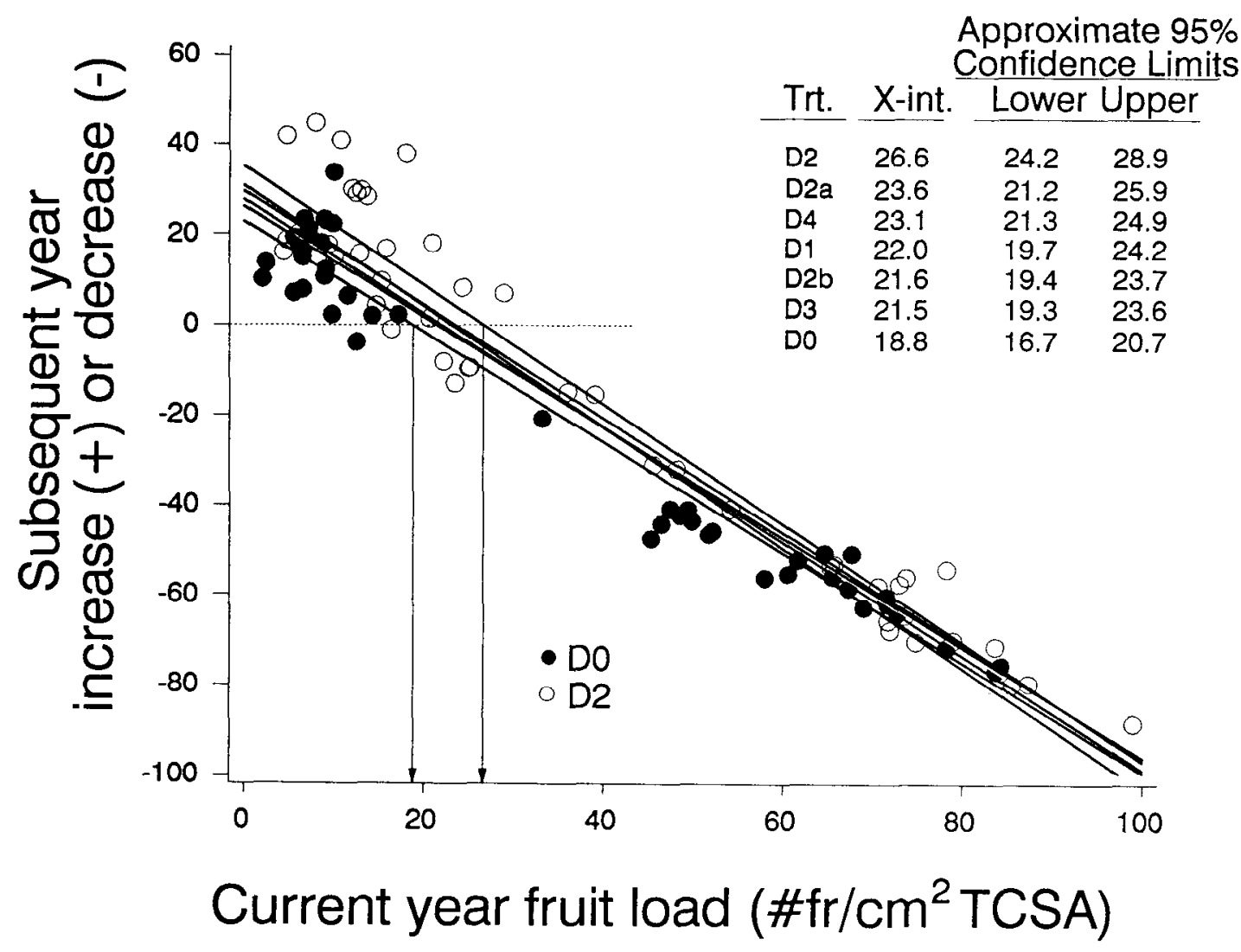

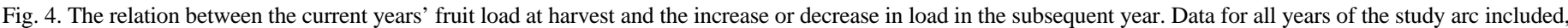
with each point representing data for an individual tree. Lines are linear regressions fitted to all points in each treatment. The point (X intercept) where each line crosses the horizontal dashed line at $\mathrm{Y}=0$ predicts the theoretical fruit load that could be carried with no change in load expected for the subsequent year. The two vertical lines shown indicate the X intercept for D0 and D2, respectively. Treatments are ranked by their corresponding X intercept, and the $\approx 95 \%$ upper and lower confidence limits for this estimate are shown. Only symbols for treatments D0 and D2 are plotted for clarity.

deficit irrigation, yet cost savings still make the strategy profitable. Since dry weight yields were not significantly impacted by the deprivation treatments in our experiments on prune, it might be an even better candidate for deficit irrigation.

Like previous work on prune, we found prune trees to be relatively tolerant of water stress. The work of Hendrickson and Veihmeyer (1934) showed that the cumulative effects of stress in prune were not enough to effect yield negatively for -5 years on the deep soils at their site. Although our study was only 3 years long, the relatively shallow soil combined with drip irrigation caused the midday stem water potential of the trees to decrease fairly rapidly upon irrigation cutoff. Although negative effects would be expected to occur more rapidly on the shallow soils in our study, they were not apparent in the three years of this study, and, in fact, the carrying capacity of the trees appeared to be enhanced by water deprivation. These results suggest that deficit irrigation has potential in managing and perhaps even increasing yields in prune.

\section{Literature Cited}

Bertrand, P.F., H. English, K. Uriu, and F.J. Schick. 1976. Late season water deficits and development of Cytospora canker in French prune. Phytopathology 66:1318-1320.

Boland, Anne-Maree, P.D. Mitchell, P.H. Jerie, and I. Goodwin. 1993. The effect of regulated deficit irrigation on tree water use and growth of peach. J. Hort. Sci. 68:261-274.

Bradford, K.J. and T.C. Hsiao. 1982. Physiological responses to moderate water stress, p. 262-312. In: O.L. Lange, P.S. Nobel, C.B. Osmond, and H. Ziegler (eds.). Physiological ecology II. Water relations and carbon assimilation. Encyclopedia of plant physiology. N.S. vol. 12B. Brown, D.S. 1953. The effects of irrigation on flower bud development and fruiting in the apricot. J. Amer. Soc. Hort. Sci. 61:2119-125.

Carpenter, E.J., A.T. Strahom, and T.W. Glassey. 1926. Soil survey of the Oroville Area, California. U.S. Dept. of Agr., Bur. Chem. and Soils. p. 43-45.

Chalmers, D.J., P.D. Mitchell, and L. van Heek. 1981. Control of peach tree growth and productivity by regulated water supply, tree density, and summer pruning. J. Amer. Soc. Hort. Sci. 106:307-312.

Chalmers, D.J., K.A. Olsson, and T.R. Jones. 1983. Water relations of peach trees and orchards. p. 197-232. In: T.T. Kozlowski (ed.). Water deficits and plant growth. Additional woody plants. vol. 7. Academic Press, New York.

Davis, L. 1931. Some carbohydrate and nitrogen constituents of alternatebearing sugar prunes associated with fruit bud formation. Hilgardia 5:119-154.

English, M., L. James, and C-F. Chen. 1990. Deficit irrigation. II. Observations in Columbia Basin. J. Irr. and Drainage Eng. 116:413426.

Goldhamer, D.A. and R.S. Snyder. 1989. Irrigation Scheduling-A guide for efficient on-farm water management. Univ. of California Div. of Agr. and Natural Resources Publ. No. 21454.

Hargreaves, G.H. and Z.A. Samani. 1984. Economic considerations of deficit irrigation. J. Irr. and Drainage Eng. 110:343-358.

Hendrickson, A.H. and F.J. Veihmeyer. 1934. Irrigationexperiments with prunes. Univ. California Agr. Expt. Sta. Bul. 573:1-44.

Hendrickson, A.H. and F.J. Veihmeyer. 1939. The effects of yields upon the apparent drying ratios of French prunes. J. Amer. Soc. Hort. Sci. 37:178-182.

Hendrickson, A.H. and F.J. Veihmeyer. 1945. Some effects of irrigation on the interrelations of growth. yields, and drying ratios of French 
prunes. J. Amer. Soc. Hort. Sci., 46:187-190.

Lambeth, C.C., W.T. Gladstone. and R.W. Stonecyhper. 1983. Stastictical efficiency of row and noncontiguous family plot in genetic test of Loblolly pine. Silvae Genetica 32:1-2.

Larson, K.D.. T.M. DeJong, and U.S. Johnson. 1988. Physiological growth responses of mature peach trees to postharvest water stress. J. Amer. Soc. Hort. Sci. 113:296-300.

Li, S.-H., J.-C;. Huguet, P.G. Schoch, and P. Orlando. 1989. Response of peach tree growth and cropping to soil water deficit at various phenological stages of fruit development. J. Hort. Sci. 61:531-552.

McCutchan, H. and K.A. Shackel. 1992. Stem water potential as a sensitive indicator of water stress in prune trees (Prunus domestca L. cv. French). J. Amer. Soc. Hort. Sci. 117:607-611.

Mitchell, P.D. and D.J. Chalmers. 1982. The effect of reduced water supply on peach tree growth and yields. J. Amer. Soc. Hort. Sci. 107:853-856.

Mitchell, P.D. and D.J. Chalmers. 1983. A comparison of microjet and point emitter (trickle) irrigation in the establishment of a high-density peach orchard. HortScience 18:472-474.

Mitchell, P.D., P.H. Jerie, and D.J. Chalmers. 1984. The effects of regulated water deficits on peal-tree growth, flowering, fruit growth. and yield. J. Amer. Soc. Hort. Sci. 109:604-606.

Mitchell, P.D., B. van den Ende. P.H. Jerie. and D.J. Chalmers. 1989. Responses of 'Bartlett' pear to withholding irrigation, regulated deficit irrigation, and tree spacing. J. Amer. Soc. Hort. Sci. 114:15-19.
Proebsting, EL.. J.E. Middleton, and M.O. Mahan. 1981. Performance of bearing cherry and prune trees under very low irrigation rates. J. Amer. Soc. Hort. Sci. 106:243-246.

Proebsting, E.L., J.E. Middleton. and S. Roberts. 1977. Altered fruiting and growth charactertistics of 'Delicious' apple associated with irrigation method. HortScience 12:349-350.

Proebsting, E.L.. P.H. Jerie. and J. Irvine. 1989. Water deficits and rooting volume modify peach tree growth and water relations. J. Amer. Soc. Hort. Sci. 114:368-372.

Ryugo, K., N. Nii, M. Iwata. and R.M. Carlton. 1977. Effect of fruiting on carbohydrate and mineral composition of stems and leaves of French prune. J. Amer. Soc. Hort. Sci. 102:813-816.

SAS Institute. 1988. SAS/STAT users guide. release 6.03. SAS Inst.. Gary. N.C. p. 597.

Steel. R.G.D. and J.H. Torrie. 1980. Principles and procedures of statistics: A biometrical approach. McGraw-Hill. New York.

Turner, N.C. 1988 Measurement of plant water status by the pressure chamber technique. Irr. Sci. 9:289-308.

Uriu, K.. C.J. Hansen. and J.J. Smith. 1962. The cracking of prunes in relation to irrigation. J. Amer. Soc. Hort. Sci. 80:211-219.

Uriu, K.1964. Effect of postharvest soil moisture depletion on subsequent yield of apricots. J. Amer. Soc. Hort. Sci. 84:93-97.

Williamson. J.G. and D.C. Coston. 1990. Planting method and irrigation rate influence vegetative and reproductive growth of peach planted at high density. J. Amer. Soc. Hort. Sci. 115:207-212. 